\title{
OS FOLCLORISTAS E A CONSTRUÇÃO DO REPENTISTA COMO UM DOS SÍMBOLOS DE NORDESTE
}

\author{
Cícero Renan Nascimento Filgueira*
}

RESUMO: O presente artigo analisa as representações dos violeiros repentistas dentro das obras dos folcloristas. Temos como corte temporal as primeiras décadas do século XX, período que começou a propagação do repentista como um símbolo do Nordeste brasileiro. Em um primeiro momento conceituamos a prática do repente que, de tipicamente interiorana, passa a ganhar o cenário das grandes cidades litorâneas. Em seguida mostramos a importância dos folcloristas (em especial Rodrigues de Carvalho, Leonardo Mota e Câmara Cascudo) no recolhimento de informações sobre esse elemento da cultura popular. No entanto, devese ter precauções ao analisá-los como fonte devido as leituras e representações que se encontram e sua obras. Portanto, utilizamos Edward P. Thompson, Michel de Certeau e Durval Muniz como referencial teórico. Por fim, abordamos a necessidade dos folcloristas, em um contexto regionalista, de introduzir o repentista como símbolo de Nordeste mantendo um distanciamento classista destes nas suas obras.

PALAVRAS-CHAVE: Cantador repentista; Cantoria de repente; Folclore; Representação.

\section{The folklorists and the construction of the "repentista" as a symbol of the Brazilian Northeast}

\begin{abstract}
The present article analyzes the representations of the "repentistas violeiros" as shown in the works of folklorists. Considering a timeframe that encompasses the first decades of the twentieth century, the period in which the propagation of the "repentista" as a symbol of the Brazilian Northeast began. At first, we conceptualized the practice of "repente", a typical practice from the countryside that starts to expand to the big coastal cities. Next, we show the importance of folklorists (especially Rodrigues de Carvalho, Leonardo Mota and Câmara Cascudo) in collecting information about this element of popular culture. However, one should take precautions when analyzing them as research sources due to the interpretations and representations that are to be found in their works. Therefore, we use Edward P. Thompson, Michel de Certeau and Durval Muniz as theoretical references. Finally, we address the need of folklorists, in a regionalist context, to introduce the "repentista" as a symbol of the Brazilian Northeast, maintaining a classist distance from them in their works. KEYWORDS: Repente singing; Repente singer; Folklore; Representation.
\end{abstract}

\section{Los folkloristas y la construcción del "repentista" como símbolo del "Nordeste"}

RESUMEN: El presente artículo analiza las representaciones de los "violeiros repentistas" dentro de las obras de los folkloristas. El corte temporal de la pesquisa son las primeras décadas del siglo XX, período que empezó la propagación del "repentista" cuanto un símbolo del Nordeste brasileño. En un primer rato conceptuamos la práctica del "repente" que, de típicamente rural, pasa a ganar el escenario de las grandes ciudades costeras. En seguida mostramos la importancia de los folkloristas (en especial Rodrigues de Carvalho, Leonardo Mota y Cámara Cascudo) en el recoger de informaciones sobre ese elemento de la cultura popular. Sin embargo, se deben tener precauciones al analizarlos como fuente debido a las lecturas y representaciones que se encuentran y sus obras. Por lo tanto, utilizamos Edward P. Thompson, Michel de Certeau y Durval Muniz cuanto referencial teórico. Por último, abordamos la necesidad de los folkloristas, en un contexto regionalista, de introducir al repentista como símbolo de Nordeste manteniendo un distanciamiento clasista de éstos en sus obras.

PALABRAS-CLAVE: Cantador repentista; Cantoria de repente; Folklore; Representación.

\footnotetext{
* Mestre em História pela Universidade Federal Rural de Pernambuco (UFRPE). Graduado em História pela Universidade Federal de Pernambuco (UFPE). Atualmente é Consultor Pedagógico (Inteligência Relacional) no Colégio e Curso Mais Fácil. Contato: Rua Doutor Milton Pina, 916, Bultrins, Olinda-PE, Brasil. E-mail: cicero_filgueira@hotmail.com.
} 
O trabalho aqui apresentado tem como principal mecanismo a análise das representações e práticas colhidas em escritos folclóricos e sua proximidade na construção de uma imagem do poeta repentista como símbolo de Nordeste, tendo como principal foco a construção e análise do que se vem a entender por repentista profissional nos dias atuais. Remeto minha pesquisa para os momentos de ruptura e permanências desta prática em fins do século XIX e início do século XX no surgimento de novos cantadores que mudam a prática e acompanham o surgimento dos torneios de cantadores (chamados de congressos), marcando assim os passos iniciais da profissionalização do violeiro repentista.

Antes de entrarmos propriamente dito na relação do folclorista com a cultura popular é inevitável uma explanação sobre o repentista no contexto da discussão que mais a frente será explanado. O repente de viola é um gênero poético de origem popular, oral, baseado em narrativas de improviso rimadas. Tem como principal função o desafio poético entre os cantadores $^{1}$. O mundo rural demonstrou grande afinidade para a propagação das práticas orais, onde, os momentos de trabalho eram arraigados por cantos, como observa Andréa Silva,

Nos momentos e nos espaços de oralidade dominante, o mundo rural era preenchido por ocupações que giravam em torno de atividades desenvolvidas nas fazendas e destinavam-se à elaboração de práticas agrícolas e pecuárias que representavam a economia local. Os momentos de trabalho eram preenchidos por cantos que embalavam os fazeres e os momentos de lazer se davam em espaços onde todos se reuniam para troca de experiências, para partilha de sonhos, para alimento de prazeres $^{2}$.

A autora ainda observa que nos momentos de lazer os espaços eram reservados às trocas de experiências diárias. São nessas circunstâncias que a cantoria de viola brasileira se desenvolve, ganhando formas no final do século XIX com os primeiros cantadores ${ }^{3}$ até os anos finais da década de 1920, com alguns repentistas adquirindo fama nacional nas mãos dos registros dos folcloristas e nos folhetos de cordel. Período este em que a cantoria começa a ganhar suas formas canônicas ${ }^{4}$, ou seja, estipulando regras, dentre as quais, o uso fixo das sextilhas e das duplas, e as pelejas passam a ser somente um momento do espetáculo. Com isso, há abertura para novos gêneros (estruturas poéticas diversas na formulação das estrofes rimadas) no repente.

No Brasil, em especial na região central do atual Nordeste, as modas de viola vindas com o colonizador português ganham feições especiais na sua prática. Os primeiros desafios poéticos, ou pelejas, eram os embates entre dois cantadores, onde, deviam-se, obrigatoriamente, dar continuidade aos versos do oponente até que um não consiga mais 
responder ao outro por não encontrar uma resposta, ou pelo fato de se sentir inadequado a continuar o combate poético. Segundo Maria Ayala e Marcos Ayala, a cantoria seria a,

Manifestação poética nordestina em que dois repentistas estabelecem uma disputa poética mais ou menos velada. Cada qual busca superar o outro, atraindo para si a atenção do público. Para isso, valem-se de grande agilidade mental, que lhes permite encontrar soluções estéticas e exibir um domínio da técnica de composição (com obediência a regras rígidas de métrica e de construção das estrofes), além de um conhecimento geral que se transforma em poesia ${ }^{5}$.

Esta definição acima citada caracteriza, primordialmente, o primeiro momento da cantoria de viola, em fins do século XIX. Pela necessidade de continuar o espetáculo e de atrair a atenção do público, vão surgindo novas formas e estruturas. Diante disto, a prática vai ganhando suas formas mais canônicas no que tange as regras, ou seja, sua estrutura definitiva.

No fim da década de 1920 passou-se a denominar "desafio" somente a situação do espetáculo em que os poetas entravam em debates. A partir disto, o campo ${ }^{6}$ dos cantadores começa a se organizar em duplas fixas amigas, no qual, alguns momentos da apresentação já eram previamente ensaiados ${ }^{7}$ ou de fácil dedução devido ao convívio constante com o parceiro. Em meio a esta nova estratégia, a apresentação ganhou novos gêneros (ou estilos) arregrados à regras. Esta prática, que se deu a partir das apropriações das antigas pelejas, pela qual vários estilos/gêneros ${ }^{8}$ são declamados, é chamada cantoria de viola, ou simplesmente: repente de viola. Os cantadores da virada do século XX começaram a estipular as primeiras mudanças na cantoria, quando esta ainda era cantada apenas em quadras.

A chegada dos cantadores no litoral, como processo migratório acentuado entre o sertão e as capitais, coincide com a cantoria se tornando sistemática, ou seja, a materialização dos gêneros desenvolvidos em fins do século XIX e início do século XX em uma prática popular. De certa maneira, compreende-se tal necessidade como os primeiros passos dos poetas a levarem a vida da viola a tiracolo como principal fonte de renda, o embrião do poeta profissional.

As cantorias no ambiente sertanejo normalmente aconteciam em residências ou festas, como casamentos. Nestas ocasiões, o mais comum para o pagamento dos cantadores era a justa, ou seja, quando era previamente acertado com o provedor do evento os valores pagos a cada poeta e, menos comum, a cantoria ingressada, onde é cobrado ingresso ao público. No entanto, quando as cantorias ocorriam em feiras, palcos improvisados, botecos, varandas, enfim, nos pés-de-parede ${ }^{9}$, o mais comum é o pagamento pela bandeja, ou seja, uma bandeja 
era sobreposta em cima de uma mesa aos pés dos cantadores ou a frente deles para que o público pagasse voluntariamente ${ }^{10}$.

Tais facetas que a cantoria adquiriu ao longo do início do século $\mathrm{XX}$ podem ser compreendidas como uma mudança nas práticas, ou um processo de ressignificação. Conforme a cantoria de viola saiu do seu seio primeiro (meio rural) em meio a apresentações em bares, casamentos e festas em geral, para ganhar uma magnitude nos grandes centros urbanos e capitais, passou a ter uma nova concepção, uma nova estrutura em meio ao exercício dos versos improvisados. Em vias gerais, os cantadores até o início do século XX não tinha o repente como forma de sustento, sendo em sua grande maioria agricultores e feirantes. Com as novas facetas trazidas com os avanços tecnológicos (rádios, estradas, trens) na virada do século XIX, a comunicação sertão-litoral tornou-se mais fácil e atrativa para aumentar a renda familiar dos poetas, ao mesmo tempo em que, ao tomar o repente como principal meio renda, deixariam de depender da instabilidade da vida no sertão (por exemplo, a agricultura sertaneja refém dos longos períodos de estiagem).

Dentre as grandes cidades litorâneas, Recife foi uma das principais a receber os repentistas e tal fato pode ser explicado não somente por uma tendência de mudança, seguindo um fluxo migratório, mas também por um mercado para as cantorias crescente no litoral, devido aos livros dos folcloristas e aos cordéis vendidos nos inúmeros mercados públicos da capital pernambucana. Sobre este fato, Ivo Leitão, em reportagem para o Diario de Pernambuco, fica surpreso ao chegar em São José do Egito (localizado no Sertão do Pajeú, em Pernambuco) e quase não encontrar mais poetas por lá. Este começa assim a matéria intitulada "Literatura popular do sertão":

O sertão começa onde termina a estrada de ferro. Com esta, as rodovias rasgando os tabuleiros e os chichi-chiques, os cantadores e repentistas estão se despedindo. São os últimos retirantes da terra calcinada. Com o cinema e o rádio penetrando, o bacharel de anel enfiado no dedo citando Freud Lin Yutang [...], a paisagem antiga modificou-se, está secando também.

- É o diabo! - cochicham os últimos remanescentes de chapéu de couro e violão, os cânones de Romano e Inacio da Catingueira, marechais das emboladas e dos desafios em todo o Nordeste. [...]. ${ }^{11}$

O objetivo da matéria era mostrar histórias do sertão e a volta de bacharéis recémformados para seus lares. Apesar do trem não chegar ao sertão, as estradas já cortavam toda região interiorana e, é perceptível na fala do repórter que, com o estreitamento das fronteiras das cidades do interior com o litoral, tornou-se atrativo para o repentista migrar para onde tinha mais público. Nota-se ainda que, para Ivo Leitão, a chegada de bacharéis nascidos na 
região, no qual haviam saído para estudar, também foi uma forma de queda do público para os cantadores nos sertões. Ao voltarem para as suas terras viram a necessidade de urbanizaram (levar a cidade) a cantoria, como será visto mais adiante no texto. Aliado a isso, a chegada do cinema e do rádio ${ }^{12}$ no interior também contribuiu para uma queda de público nos espetáculos de cantador, já que se caracterizavam como uma forma alternativa de entretimento.

Os folcloristas foram de fundamental importância no que se refere à divulgação das práticas dos repentistas nos centros urbanos. No entanto, neste ínterim, o trabalho analítico dos textos folclóricos merece uma atenção especial por dois motivos: primeiro, por se tratarem de uma tradição que remete ao século XIX de estudos voltados a buscar informações em geral do que era chamado de "alma do povo"; segundo, muito dos textos jornalísticos publicados entre 1930 e 1950 nota-se que a maioria dos autores reproduz os discursos dos folcloristas, denotando assim, uma forte influência de como a população letrada tomou conhecimento dos repentistas. Logo, o manuseio com esse tipo de fonte carece um cuidado especial como apontam alguns estudiosos. O historiador britânico Edward P. Thompson atenta para fato que a utilização dos escritos dos folcloristas deve sempre ser vista com cautela para não reproduzir o discurso desses na escrita do texto científico. Thompson, ao levantar o material dos folcloristas durante a pesquisa para escrever A formação da classe operária inglesa, ficou inquieto ao notar que,

O costume e o ritual foram frequentemente encarados pelo cavalheiro paternal - e estrangeiro (no caso da Índia) - a partir de cima e por cima de uma fronteira de classe, sendo ainda divorciados de sua situação ou contexto. As perguntas dos folcloristas raramente procuravam saber da sua função ou uso corrente. Antes, os costumes eram vistos como "relíquias" de uma antiguidade remota e perdida, como ruínas desmoronadas $[\ldots]^{13}$

À medida que é reproduzido no discurso dos folcloristas é criado percepção de uma cultura em extinção, é adotável o que Michel de Certeau ${ }^{14}$ chama de Beleza do Morto. Neste processo, descreve como a cultura popular era encarada pelas elites e a necessidade que estas tinham em primeiro esquecer (censurar) o popular para então "ressuscitar" (ser estudadas/divulgadas). Com isso, procuramos compreender que a cantoria de viola "[...] só pode ser interpretado quando as fontes (algumas delas coletadas por folcloristas) deixam de ser olhadas como fragmento folclórico, uma 'sobrevivência', e são reinseridas no seu contexto total" ${ }^{\prime 2}$. Historiadores, como Durval Muniz, na análise da formação do movimento folclórico no Nordeste também atentam para fato da "salvação" do popular. Segundo este, o mundo oral era potencialmente perigoso para as elites e, ao passo que este mundo é transferido para a 
linguagem escrita (registro dos folcloristas) significava uma tradução dos gestos, das atitudes, dos rituais, etc., portanto, o trabalho folclórico representava atividades de seleção e censura ${ }^{16}$.

Para estudar o discurso dos folcloristas aqui analisados é necessário explanar como se deu o desenvolvimento desta prática no Brasil. O movimento folclórico já vinha forte no Brasil desde a metade do século XIX, no que Renato Ortiz ${ }^{17}$ chama de Período Romântico do folclore brasileiro. A chegada do folclorismo no Brasil remete, em parte, a grande atuação dos Irmãos Grimm (Jacob e Wilhelm Grimm), linguistas e poetas alemães que, sob forte influência do movimento romântico alemão, registraram contos populares, principalmente infantis, e ganharam grande notoriedade internacional. O termo "folclore" fora adotado pela primeira vez em meados do século XIX pelo arqueólogo inglês Willian John Thoms e é construído na junção de folk (povo) e lore (saber). Logo, o novo termo passa a ser adotado e substitui outras expressões, como "literatura popular" e "antiguidades populares", que representavam a prática do registro das tradições transmitidas oralmente no campesinato ${ }^{18}$. Portanto, o termo "folclore" não pode ser naturalizado, logo, se encaixa dentro de uma concepção de história dos conceitos, ou seja, longe de ser um elemento fixo e estático, o conceito reflete uma noção política atual no espaço e tempo da sociedade que a cria ${ }^{19}$. Já no início do século XX os estudos do folclore se concentravam basicamente na poesia de origem popular, a chamada literatura oral. Somente por volta dos anos de 1950 que os folguedos populares ganham maior notoriedade nos estudos folclóricos.

O período romântico é caracterizado pela valorização do positivismo, em alta entre fins do século XVIII e início do século XIX. Os intelectuais deste período tinham um grande interesse pelo que consideravam pitoresco. Os que se dedicaram a esse tema foram os responsáveis pela criação de um popular ingênuo e anônimo, alma da nacionalidade ${ }^{20}$. Para os românticos, o povo seria um elemento primitivo, autêntico e restringia-se basicamente ao meio rural. Além disso, havia um forte sentimento nostálgico que, segundo Ortiz, "tratava-se de lutar contra o tempo. O esforço de colecionador identifica-se à ideia de salvação; a missão é agora congelar o passado, recuperando-o como patrimônio histórico" ${ }^{21}$.

Dentro dessa perspectiva, Durval Muniz observa que ao mesmo tempo em que o folclorista procura a salvação do morto, do que está em viés de escassez, tem em sua fala uma tentativa de significar a manutenção de um discurso conservador. Ou seja, a partir do momento que a sociedade entra num processo de globalização e alteração de práticas culturais (a exemplo do divórcio, voto feminino, etc.), "salvar o morto" como símbolo nacional representaria a manutenção de antigas tradições sociais. Para o historiador, "uma história feita 
de conservações e não de mudanças, rupturas, de descontinuidades, de deslocamentos" Ortiz viu esse cenário inicial contrastante, pois, ao passo que se pregava o progresso da Revolução Industrial travestido em uma modernidade ligada aos técnicos, administradores, etc., em contrapartida, os intelectuais românticos representavam o "intelectual tradicional”, ou seja, "nadam contra a corrente, e procuram armazenar, em seus museus e bibliotecas a maior quantidade possível de beleza morta" 23 .

É, em meio a esse cenário, que surgem os primeiros estudiosos folcloristas no Brasil. A preocupação inicial estava relacionada à identidade nacional sendo mais urgente responder questionamentos, tais como: “Quem somos?" ou "quem nós não somos?”. Dois são os sentidos nas reflexões que estes fazem: o primeiro deles advém por uma compreensão da sociedade, logo, passa por análises sociológicas, históricas e antropológicas; o segundo, como acima afirmado, estava relacionado ao destino, ou seja, precisavam entender quem eram. Esse tipo de debate englobou vários estamentos da elite nacional envolvendo profissionais como médicos, engenheiros e advogados. Para Ortiz,

[...] a ideia fundamental que marca esta discussão é a de "falta", de "ausência". Pode-se enumerar várias maneiras como o tema foi abordado, mas existe uma constante, que atravessa o século, um vetor convergindo sempre para o mesmo horizonte: a identidade nacional ${ }^{24}$.

Tais inquietudes foram as temáticas dos nossos primeiros folcloristas, em meados do século XIX, como Silvio Romero, Celso de Magalhães e Couto de Magalhães. Estes acreditavam que a identidade nacional seria alcançada entrando em contato com as manifestações populares, mesmo que este contato não seja direto com os praticantes da manifestação cultural.

Quando refere-se especificamente ao "nascimento" da poesia popular no Nordeste, a fim de posicionar o cancioneiro como um elemento representante de uma identidade primeira do nordestino, alguns estudiosos tornam-se referências. Em um primeiro momento no século XIX, destaca-se Silvio Romero. Já nas primeiras décadas do século XX se sobressaem Rodrigues de Carvalho, Leonardo Mota e Câmara Cascudo. Doravante, há outros expoentes de fundamental importância, porém, este trabalho atentará aos três supracitados devido a importâncias nos primeiros momentos da década de 1920, quando se fortalece as urgências regionalistas.

$\mathrm{Na}$ busca por compreender mais sobre o universo da cantoria de viola durante o período proposto - das antigas pelejas na virada do século XIX até os surgimentos dos 
congressos nos anos 1940 do século XX -, os citados folcloristas tornam-se referências, pois, são os primeiros a trabalhar de forma a quebrar o anonimato dos cantadores sertanejos. Com isso, é possível identificar a cantoria de viola e seus agentes. Dentre as produções aqui utilizadas estão: Rodrigues de Carvalho com Cancioneiro do Norte (1903); Leonardo Mota com Cantadores: poesia e linguagem do sertão cearense (1921), Violeiros do Note: Poesia e linguagem do Sertão Nordestino (1925) e Sertão Alegre: Poesia e linguagem do Sertão Nordestino (1928); Câmara Cascudo, principalmente em Vaqueiros e Cantadores (1939) e Literatura Oral no Brasil (1952).

Mas como se deu o processo de aproximação do cantador como símbolo do Nordeste? Recife a partir de 1930 se tornou um grande centro urbano devido ao crescimento populacional e ao seu comércio que se tornou bastante vigoroso. Consequentemente, se firmando como um polo econômico, também houve o crescimento nas produções intelectuais desta cidade. A Faculdade de Direito do Recife foi a grande responsável pela movimentação dos filhos das elites dos estados da área inicialmente chamada de Nordeste (Pernambuco, Paraíba, Rio Grande do Norte e Ceará). Entre os bacharéis circulavam grandes debates e troca de ideias que, mais tarde, levariam para seus estados e, em muitos casos, tais bacharéis tornaram-se governantes em seus estados 25 .

É neste contexto que, pela inspiração de Gilberto Freyre, o Centro Regionalista do Nordeste foi criado em nove de setembro de 1924: "Data em que ocorre um acontecimento decisivo para a emergência do que se conhece hoje como sendo a cultura popular nordestina" ${ }^{26}$, encontraram-se na casa de Odilon Nestor ${ }^{27}$ (1875-1968) no bairro da Boa Vista em Recife, com o intuito de defender as tradições e promover os interesses pelo Nordeste, alguns dos principais nomes no cenário intelectual dos estudos da cultura nordestina. Dentre eles estavam: Gilberto Freyre (escritor e sociólogo pernambucano); Leonardo Mota (folclorista cearense); Joaquim Nogueira (ex-governador do Piauí); Câmara Cascudo (folclorista, escritor e jornalista do Rio Grande do Norte). Para este contexto, é importante frisar que a historiografia atribui à ideia de um Centro Regionalista, porém, é controverso, já que foi um encontro informal e sem construção de manifestos ou algo do gênero. Para esta pesquisa, me atento a ideia crescente de regionalismo que se tornou mais frequente e forte a partir da década de 1920.

A demanda regionalista/tradicionalista ganhou força na missão de desenvolver o sentimento de unidade do Nordeste e, entre 7 e 11 de fevereiro de 1926, foi instalado o I Congresso Regionalista do Nordeste, com uma extensa programação. A cessão de abertura foi 
no auditório da Faculdade de Direito do Recife e, entre as pautas, estava desde: tratar de problemas econômicos e sociais; discutir a unificação econômica do Nordeste, problemas rurais, florestais no Nordeste; defesa do patrimônio artístico e dos monumentos históricos; entre outras temáticas. Teve também reuniões no salão de conferências do Departamento de Saúde e Assistência, onde, várias teses de estudos da cultura nordestina foram apresentadas ${ }^{28}$.

O termo "Nordeste" é usado oficialmente pela primeira vez, em 1919, pela IFOCS (Inspetoria Federal de Obras Contra as Secas), no qual, designava o Nordeste como sendo uma parte da região Norte assolada por secas constantes e, com isso, necessitava de uma atenção especial por parte do poder central ${ }^{29}$. Durval Muniz ${ }^{30}$ acentua que as secas, em especial a de 1877-79, que começaram a difundir a região nos periódicos do Sul. Logo, a ideia da região Nordeste ser sinônimo de flagelo social ganha notoriedade nas populações sulistas. Com isso, a superação dessa visão e a construção de um Nordeste separado dos estados do Norte é a grande missão político-cultural na institucionalização do Nordeste. Nesse contexto, Durval salienta a importância do Centro Regionalista na promoção do congresso acima citado, no qual,

[...] se propunha a "colaborar com todos os movimentos políticos que visassem ao desenvolvimento moral e material do Nordeste e defender os interesses do Nordeste em solidariedade". Dizia o programa do Centro que a unidade do Nordeste já estava claramente definida, embora assumisse também, como uma de suas tarefas, acabar com os particularismos provincianos para criar a comunhão regional. ${ }^{31}$

As contribuições desta demanda regionalista/tradicionalista estão visíveis nos jornais recifenses mesmo na década de $1940^{32}$, principalmente pela forte visibilidade que as práticas culturais nordestinas ganharam ao longo da década de 1930 com as publicações de Gilberto Freyre $^{33}$. E em especial, ao que se refere ao universo do repente de viola, três folcloristas se destacam para este trabalho: Rodrigues de Carvalho, Leonardo Mota e Câmara Cascudo. Neste ínterim, os cantadores e o folclore nordestino já tinha certa divulgação, principalmente em propagandas de festas, mas também quando os repentistas eram temas acadêmicos, como,

Por iniciativa da Diretoria de Estatística, Propaganda e Turismo, com cooperação da Força Policial do Estado foi proporcionado ontem ao prof. Curt Lange, no Nucleo Operario do Prado, uma exibição de cantadores e violeiros do sertão. Foram executados números de viola, de sanfona, tendo havido vários desafios. [...] O prof. Curt Lange interessou-se pelos cantadores, colhendo, na ocasião várias informações que se relacionam aos seus trabalhos de pesquisa nesta região. $\mathrm{O}$ grupo estava assim constituído: Otacílio Batista Patriota, José Duda Neto, João Francisco d'Oliveira e Pedro José da Silva, Violeiros.

[...] A DEPT irá gravar todas as composições apresentadas, uma vez que se tratam de melodias típicas, que tendem, infelizmente, a desaparecer como efeito da descaracterização crescente da zona onde são comuns ${ }^{34}$. 
Na matéria, referente a visita do musicólogo teuto-uruguaio Curt Lange à Recife, a fim de ouvir os cantadores em sua pesquisa de campo para levantamento da cultura da América Latina, observa-se ainda (em destaque) a reprodução do discurso folclorista da necessidade de estudar o estava por morrer, o que representa o Nordeste. Logo, com relação à adesão dos folcloristas ao movimento, Durval Muniz afirma que é

[...] fundamental para a emergência da ideia de Nordeste, mobilizou fundamentalmente os intelectuais e políticos daqueles quatro Estados, o que pode explicar a adesão desses estudiosos do folclore e esta identidade regional. ${ }^{35}$

O que levou os folcloristas a ganhar prestígio no cenário nacional foi o empenho no levantamento biográfico de poetas e o excessivo trabalho de registro de canções. No entanto, tais registro passaram pelo crivo de escritos inseridos em uma outra realidade social e, consequentemente, foi refletido em suas obras o olhar elitista para com o popular. Logo na virada do século XX, em 1903, o paraibano Rodrigues de Carvalho publicou o Cancioneiro do Norte. O pioneirismo de Rodrigues não consistiu somente no levantamento de manifestações populares (desafios, cocos, lendas, folguedos, bumbas-meu-boi, cantigas de São João, etc.), mas sim, em trabalhar com a poesia popular procurando autoria, ou seja, os cantadores. Com isso, seguindo contra a corrente, quebra o anonimato do folclore, procurou fazer um levantamento sobre quem eram esses cantadores que perambulavam pelo sertão no fim do século XIX. Outro fator do ineditismo na obra deste está relacionado ao levantamento e análise dos gêneros da cantoria ao longo da introdução na primeira edição, onde, pode-se notar o uso da quadra, do mourão, da sextilha, da décima e do martelo pelos cantadores que entraram no século XX.

Decerto, seria anacronismo inserir Rodrigues em um movimento que somente ganha força vinte anos após sua publicação, porém, como salienta Durval Muniz, foi na segunda edição de Cancioneiro do Norte, de 1928, que o folclorista adere à ideia de cultura nordestina. Com isso, "será sempre considerado pelos que o seguem como um livro precursor dos estudos dessa cultural" 36 .

Rodrigues, considerado por Câmara Cascudo como uma bibliografia básica nos estudos de folclore, em suas páginas dedicadas as "Notas sobre cantadores", começa descrevendo suas impressões sobre os cantadores. Afirmou: 
prazeres e folgares: o cantador popular. Quase sempre desocupado, sem profissão classificada entre as classes laboriosas, boêmio por índole, valentão e desordeiro, seduzindo mulheres, dominando a canalha; eis o trovador do povo, a perambular de povoado em povoado, adivinhando casamentos e batizados, de viola ao peito, faca de ponta à cinta, lenço de ganga ao pescoço, cabelos em cachos sôbre a testa, usando jaqueta e camisa muito anilada. ${ }^{37}$

Sistematicamente, suas observações foram criadas a partir de relatos, ao passo que o folclorista não fez um estudo de campo colhendo informações. A partir do momento que sua obra é considerada referência, passou a promover uma ideia genérica da imagem de cantador de viola. Mais a frente, ainda em suas notas, o folclorista descreveu o repentista com características imutáveis, afirmando:

O cantador anda invariavelmente aguardentado. Do domingo ao sábado, pernoitado, olhos raiados de sangue, vai de povoado em povoado, de fazenda em fazenda, em sua fainha de ganhar a vida cantando, ora em desafios picarescos, ora em louvaminha barata ao seu coronel, ou à filha dêste, a Sinhàzinha, moçoila gentil, que nem sempre vem à sala, quando há visita de homem estranho em casa. ${ }^{38}$

Nota-se que, em seu texto, o uso de termo como "invariavelmente" remete a uma imagem fixa, predeterminada, do repentista. Um conceito estigmatizado de boêmio alcoólatra, arruaceiro, etc. Esse tipo de postura começou a ser abandonada com mais assiduidade em meados do século XX, com a entrada de novos cantadores no cenário nacional que, em alguns casos, chegam a ser comparados a famosos artistas eruditos.

O segundo aqui destacado em ordem de produção é o cearense Leonardo Mota. Este é peculiarmente importante na construção da ideia de Nordeste. Tendo como principais obras: Cantadores: poesia e linguagem do sertão cearense (1921), Violeiros do Note: Poesia e linguagem do Sertão Nordestino (1925) e Sertão Alegre: Poesia e linguagem do Sertão Nordestino (1928).

O pioneirismo de Leonardo Mota está no trato com os cantadores, pois, fez suas pesquisas convivendo com os poetas, entrevistando-os, levando-os para sua residência, etc. Câmara Cascudo, no prefácio de Cantadores, disserta sobre o fato de, apesar de já terem existidos outros trabalhos que se referiam ao cancioneiro popular, somente com a contribuição de Mota, que tais cantadores saem “detrás da cantoria”. Afirmou Cascudo:

Com o CANTADORES (1921) Leonardo Mota divulga a figura do produtor da poesia sertaneja. Tínhamos uma certa abundância desse material, colhido e salvo especialmente por Silvio Romero (1883) e a contribuição meritória de Rodrigues de Carvalho (1903) e Pereira da Costa (1908). Nesse 1921 Gustavo Barroso publicava a primeira antologia do folclore em prosa e verso nordestino, "Ao som da viola". Mas o cantador estava escondido detrás da cantoria, oculto pela floração. Ninguém sabia, de moro geral, a história deles, como viviam, produziam, decoravam, enfim, a 
mecânica do desafio. Ignorava-se a galeria daqueles valores humanos, as fisionomias, a gesta ${ }^{39}$.

Leonardo Mota, ao contrário de seus predecessor Rodrigues de Carvalho nos estudos folclóricos, foi a campo recolher informações, taquigrafar poesias, biografar cantadores contemporâneos, tornando-os famosos entre os leitores da elite letrada urbana.

Para Durval Muniz ${ }^{40}$, as ideias oriundas do que seria o Centro Regionalista foi de fundamental importância nos escritos de Mota. Diálogos e ideias construídas, principalmente, entre Leonardo Mota e Câmara Cascudo. Fato observado na série de prefácios que Cascudo faz das obras de Mota. Este já era folclorista de renome com a publicação de Cantadores, em 1921, enquanto Cascudo apenas havia iniciado seus estudos folclóricos e teria algumas poucas publicações no jornal A Imprensa.

As produções subsequentes de Mota passam a incorporar a ideia de Nordeste. O folclorista deixa de descrever a cultura popular direcionada ao Ceará e passa a descrever elementos de uma cultura popular nordestina, ou seja, "passa a usar a designação nordestina para nomear e definir os materiais culturais populares que recolhera e que organizava em forma de livro" $"$. Pode-se usar como exemplo dessa mudança os títulos dos seus livros após o encontro de 1924: o livro Cantadores tinha como subtítulo "poesia e linguagem do sertão cearense", todavia, um ano após o encontro em Recife, ainda publica um livro denominado Violeiro do Norte $^{42}$ e, desta vez, o subtítulo passa a ser "poesia e linguagem do sertão nordestino"43.

Assim como outros folcloristas contemporâneos e os do final do século XIX, Mota se refere aos repentistas com certa distância. Como membro da elite rural, este se via acima, em uma fronteira de classe. No entanto, o folclorista cearense levou em um tom, por certo, mais leve que seu predecessor, Rodrigues de Carvalho. Mesmo quando os temas coincidem. Mota escreveu sobre o alcoolismo entre os cantadores:

Do meu convívio com os cantadores me resta suficiente autoridade para garantir que
os cantadores, que são também "homens de inteligência e grandes lúcidos", não
gostam de água mineral. Entre os mortos tenho notícia de muitos que iam à
perfeição de não abusar, sequer, da água do pote, embora não repetissem a velhaca
escusa daquele boêmio que se abstinha do uso da água, para não roubar o pão às
pobres lavadeiras... ${ }^{4}$

Obviamente, o gosto particular dos repentistas não era motivo de julgamento préestabelecido ou, pelo contrário, como o próprio Leonardo Mota defendeu, eram "homens de inteligência e grandes lúcidos". Anos depois, quando Orlando Tejo ${ }^{45}$ se referindo a um dos 
maiores repentistas do século XX, Severino Pinto, e o fato deste gostar de bebida alcóolica não é levado em consideração ao estipular seu caráter ${ }^{46}$.

Leonardo Mota, ao longo dos anos 1920 e 1930, apresentou-se inúmeras vezes no Recife. Suas palestras o tornaram cada vez mais famoso por entre a elite. Estas palestras, lembra Durval Muniz ${ }^{47}$, foram responsáveis pela urbanização (trazer à cidades) a figura do cantador, de apresenta-los as elites letradas dos grandes centros. Constantemente, os jornais da capital pernambucana expunham propagandas das audições do folclorista assim como notas sobre de suas viagens pelo sul do país. Chegou-se, inclusive, a ser publicado resumo de seus livros, principalmente, do pioneiro Cantadores.

Mota, em uma de suas apresentações, assumiu tom em defesa dos repentistas. Em Violeiros do Norte, onde transcreveu trechos dessa palestra proferida em Fortaleza, fez duras críticas às populações litorâneas, principalmente, das regiões mais ao sul do Nordeste do Brasil que tratavam com preconceitos os cantadores e a população sertaneja em geral.

No Rio de Janeiro, em doze capitais de Estado e nas principais cidades de S. Paulo e Minas, populosos centros urbanos patrícios que visitei há três anos, todo me devotei a uma campanha de morigerado nacionalismo, refutando a velha injustiça de as populações litorâneas ou citadinas só enxergarem no sertanejo ou o cangaceiro de alma de lama e de aço a que reporta Gustavo Barroso, ou o ser desfibrado e lerdo que magina, de cócoras e tão inexoravelmente caricaturado por Monteiro Lobato. ${ }^{48}$

Mota ao referir-se das palestras proferidas por vários estados, nas quais, procurou quebrar a ideia de sertanejos como inferiores, bêbados, lerdos, inúteis, etc. Nota-se ainda na sua fala a defesa do jeca caricaturado nas obras de Monteiro Lobato, quando este se referia ao sertão (interior) paulista e não ao interior do Nordeste. Mais a frente, em seu discurso, o folclorista deixou claro seus objetivos nas palestras: “[...]reivindicando o bom nome dos habitantes do Interior, estigmatizei o fato de sòmente cair no gosto das multidões $\mathrm{o}$ julgamento pejorativo da raça, mercê das 'generalizações estouvadas' e dos 'erros de sociologia leviana", 49

Leonardo Mota propôs uma nova imagem do sertanejo (repentista) trazendo este à tona e quebrando estigmas, "que nos sertões do Nordeste não vegeta molemente uma patuléia de inúteis" ${ }^{\text {"50 }}$. Desenvolveu em seu texto argumentos que levam a defesa dos sertanejos, a uma nova visão sem preconceitos, enumerando pensadores e escritores que comungavam de sua ideia: de que o "Jeca Tatu não é uma síntese nem fisiológica, nem psíquica, nem econômica, nem política" ${ }^{, 51}$. Encerrando sua linha de pensamento, o folclorista em tom de desabafo afirmou: 
Fui assim, meus Srs., fui, como estais vendo, fui intransigente na defesa do sertão esquecido, do sertão ridicularizado, do sertão caluniado e só lembrado quando dêle se quer o imposto nos tempos de paz ou o soldado nos tempos de guerra. E foi, sobretudo, contra o labéu de cretinice do sertanejo nordestino que orientei a minha documenta contradita: em todo o meu "Cantadores" e nas conferências que proferi, de Norte a Sul, pus o melhor dos meus empenhos em fazer ressaltar a acuidade, a destreza de espírito, a vivacidade da desaproveitada inteligência sertaneja, de que os menestréis plebeus são a expressão bizarra e esquecida, apesar de digna de estudos. $^{52}$

Mota, ao longo dos seus textos, evita fazer julgamentos como os de Rodrigues de Carvalho, até mesmo quando se distancia dos repentistas com o olhar de estrangeiro ao expressar-se às poesias sertanejas como sendo bizarras, pitorescas, etc. $\mathrm{O}$ autor se concentra, ao longo de sua narrativa, descrevendo os fatos ouvidos ou presenciados em suas viagens, assim como a análise das poesias, sempre destacando a inteligência e presunção dos poetas. Esse tipo de postura que o folclorista mantém é compreendido dentro de um contexto, no qual, a elite rural (a qual ele pertencia) viu no elemento popular (o cantador) um aliado na defesa do modo vida que desejava manter. ${ }^{53}$

Por fim, e não menos importante, destaca-se Câmara Cascudo. Este, ao contrário de Mota, demorou um pouco mais para lançar um livro dedicado ao folclore. Somente em 1939 lança Vaqueiros e Cantadores: folclore poético do sertão do Ceará, Paraíba, Rio Grande do Norte e Pernambuco. Nota-se que, diferentemente de Leonardo Mota, não anexa de início o termo Nordeste nos seus escritos ${ }^{54}$, como pôde-se notar no subtítulo da primeira edição da citada obra.

Em Vaqueiros e Cantadores, Cascudo fez um levantamento de materiais separando-os por tipo: Romances, Pé-quebrado, Os A.B.C., Pelo-Sinais, Ciclo do Gado, Ciclo Social (Pe. Cícero, Louvor e Deslouvor das Damas, O Cangaceiro), etc. Ainda promove um longo estudo sobre o que considera ser os antecedentes da cantoria, os instrumentos, temas, etc. Ao fim deste livro dedicou biografias aos famosos cantadores do século XIX.

Cascudo fez uma vasta produção escrita sobre o folclore. No tocante da cantoria, lançou também, em 1952, Literatura Oral no Brasil. Ao longo de suas produções o folclorista mantém um tom que deixa os agentes do folclore estáticos, como peça de museu ${ }^{55}$, no qual, a sociedade deveria se espelhar como elemento dignificador. Com relação a esse fato, Durval Muniz afirma:

Seus estudos, longe de fazer uma análise histórica ou socióloga do dado folclórico, se constituem em verdadeiras coletâneas de materiais referentes à sociedade rural, patriarcal e pré-capitalista do Nordeste, vendo o folclore como um elemento 
decisivo na defesa da autenticidade regional, contra os fluxos culturais cosmopolitas. 56

No que se refere à origem do fenômeno da cantoria de viola no Nordeste, dois pontos nas obras de Câmara Cascudo chamam atenção: os temas referentes às influências africanas e indígenas na cultura da viola. Para o folclorista, a cultura indígena em nada contribuiu para a poesia do desafio, onde, ao citar estudos como o Gabriel de Souza, Carfim, Léry, entre outros, afirma que os cânticos indígenas eram em grupos e pouquíssimas eram os casos de improviso, ou seja, para o autor, não haveria registros entres os ameríndios de uma poética do improviso. Com isso, podemos afirmar que a proposta de Cascudo não leva em consideração o longo percurso de mútuas influências que as relações entre grupos culturais distintos tomam ao longo do tempo. Logo, ao passo que colonização dos sertões se deu em muito com as entradas e com os conflitos com os indígenas locais ${ }^{57}$, é quase impossível dizer que as regiões onde se proliferou a cultura do repente de viola, as populações que ali se fixaram não sofreram trocas mútuas de experiências e costumes com a cultura indígena.

O mesmo se aplica a influência africana. Ao afirmar que não havia entre os africanos nada de semelhante com a cantoria do sertão nordestino, Cascudo cai no mesmo engano, pois, quando este leva em consideração a forte influência moura nas formas poéticas brasileiras, não se atentou ao fato de que a invasão moura à Península Ibérica se deu pelo norte da África, no qual, cem anos foi o tempo que os árabes começaram a expandir seus domínios políticos na África até que começou a penetrar na Península Ibérica, em 711. ${ }^{58}$

Por fim, destaca-se ainda em Cascudo como este representava a figura do repentista em suas obras. Em Vaqueiros e Cantadores, os poetas do improviso são retratados semelhante a visão de Rodrigues de Carvalho. No capítulo "Cantador", Cascudo repassa toda sua impressão eurocentrista do que seria o cantador: o descendente dos aedos grego, do rapsodo ambulante, metris árabes em Al-Andalus, etc. Em dado momento, se remeteu aos cantadores nordestinos da seguinte maneira: "curiosa é a figura do cantador. Tem ele todo orgulho do seu estado. Sabe que é uma marca de superioridade ambiental, um sinal de elevação, de supremacia, de predomínio"59. Mesmo que elevando a importância do repentista por entre a população interiorana, o folclorista em Dicionário do Folclore Brasileiro ${ }^{60}$, acrescentou ao pensamento acima: "analfabetos ou semiletrados, têm domínio do povo que os ama e compreende" ${ }^{\prime 61}$, mesmo que, em sua obra anterior, tenha amenizado o analfabetismo entre os repentistas, onde "a percentagem hoje é inferior a $20 \%$ ", isso em 1939 , ano do lançamento do livro. 
A cantoria de viola, em Câmara Cascudo, foi promovida ao elemento dignificador da cultura popular. Mesmo assim, não deixou de pré-julgar seus praticantes, pejorativamente, classificando-os com uma série de adjetivos, tais como: "paupérrimo, andrajoso, semifaminto, errante, ostenta, num diapasão de consciente prestígio, os valores da inteligência inculta e brava, mas senhora de si, reverenciada e dominadora" ${ }^{\natural 3}$. O prestígio, como dito, é seguido de uma inteligência classificada como inculta. Esse tipo de postura, novamente foi reflexo de um distanciamento que os folcloristas mantinham do seu elemento de estudo. A visão de um estrangeiro de uma classe dita superior garantida por seu posicionamento social e sua formação intelectual.

Os repentistas perdem anonimato com os folcloristas, no entanto, não é o mesmo que ocorre nos jornais. Os cantadores demoram mais alguns anos para começar a ganhar nomes com mais frequências nas páginas dos periódicos, mais precisamente somente depois que estes se aproximam dos palcos de teatro. Nota-se, portanto, que progressivamente o repente de viola passa a ser considerado como símbolo de um Nordeste que surgia era também elevado a elemento dignificador da moral e ética de uma sociedade que estava em mudança. Por vezes, esse fato variou quando o tema era diretamente o sujeito cantador, ao passo que este representava uma cultura dignificadora. Porém, deveria ter os hábitos que os manteria inferiores aos que os representava na elite.

\section{Notas}

\footnotetext{
${ }^{1}$ Cf. AYALA, Maria Ignez Novais. No arranco do grito: (aspectos da cantoria nordestina). Ática, 1988.

2 SILVA, Andréa Betânia da. Entre pés-de-parede e festivais : rota(s) das poéticas orais na cantoria de improviso. Tese (doutorado) - Universidade Federal da Bahia, Instituto de Humanidades, Artes e Ciências Prof. Milton Santos. I'Université Paris Ouest Nanterre, 2014. p. 25.

3 Aqui chamamos de primeiros cantadores os que ficaram no conhecimento popular, apontados pelos folcloristas, como sendo os pioneiros. A literatura apresenta como o mais antigo cantador Agostinho Nunes da Costa (1797-1858). Cf. ALMEIDA, Átila. Notas sobre a poesia popular. Campina Grande:[s.n], 1984.

${ }_{5}^{4}$ ABREU, Márcia. Histórias de cordéis e folhetos. Campinas: Mercado das letras, 1999. pp. 73-90.

5 AYALA, Marcos; AYALA, Maria Ignez Novais. Cultura popular no Brasil: perspectiva de análise. Ática, 1987. p. 69.

${ }^{6}$ Entende-se por campo a construção nos espaços sociais onde as práticas individuais e coletivas se dão de forma normatizada através das tenções dentro dos agentes da prática cultural. Cf. BOURDIEU, Pierre. O poder simbólico. Rio de Janeiro: Bertrand Brasil, 2003.

7 ABREU, Márcia. Op. Cit. 1999. pp. 73-90. Essa mudança na dinâmica da cantoria é compreendida, na dissertação que deu origem a este artigo, dentro de uma série de apropriações que uma leva de cantadores, que chamei de "Geração Moderna" fizeram das antigas tradições. Esse tipo de conduta, mesmo que involuntariamente, significa causar uma distinção entre os novos praticantes e os praticantes aqui chamados de clássicos. Concordando com Roger

Chartier quando este afirma: “[...] em toda sociedade, as formas de apropriação dos textos, dos códigos, dos modelos compartilhados são tão ou mais geradoras de distinção que as práticas próprias de cada grupo social"
} 
CHARTIER, Roger. Cultura Popular revisitando um conceito historiográfico. In: Estudos Históricos, Rio de Janeiro, vol. 8, no. 16, 1995, p. 184.

${ }^{8}$ Vários gêneros surgem no início do século XX, como por exemplo: décimas, martelo, mourão, gemedeira. Todos estes apresentam suas peculiaridades e níveis de dificuldade. Cf. ALMEIDA; SOBRINHO, Op. Cit. 1978.

${ }^{9}$ Como também é chamado o repente de viola.

${ }^{10}$ AYALA, 1988. pp. 23-33.

${ }^{11}$ Diario de Pernambuco, 21 ago. 1946. Acervo Biblioteca Nacional.

${ }^{12}$ Nota-se ao passar dos anos que o rádio tornou-se um grande aliado dos poetas, onde, muitos ganharam seus próprios programas e a poesia foi largamente divulgada.

${ }^{13}$ THOMPSON, Edward Palmer. Folclore, Antropologia e História Social. In: ; NEGRO, Antonio Luigi; SILVA, Sergio (orgs.). As peculiaridades dos ingleses e outros artigos. São Paulo: Editora da Unicamp, 2012. p. 231.

${ }^{4}$ CERTEAU, Michel de. A beleza do morto. In: A cultura no plural. São Paulo: Papirus, 1995. pp. 55-86.

${ }^{15}$ THOMPSON, 2012, p. 238.

16 Cf. ALBUQUERQUE JÚNIOR, Durval Muniz de. "O morto vestido para um ato inaugural": procedimentos e práticas dos estudos de folclore e cultura popular. São Paulo: Intermeios, $2013 \mathrm{~b}$.

${ }_{17}^{17}$ ORTIZ, Renato. Românticos e folcloristas: cultura popular. Olho d'água, 1992. p. 36.

${ }^{18}$ VILHENA, Luís Rodolfo. Projeto e missão: o movimento folclórico brasileiro, 1947-1964. Fundação Getulio Vargas Editora, 1997. pp. 24-25.

${ }^{19}$ KOSELLECK, Reinhart. Futuro Passado: Contribuições à semântica dos tempos históricos. Puc-Rio. 2006. p. 98.

${ }^{20}$ VILHENA, 1997, p. 25.

${ }^{21}$ ORTIZ, 1992, p. 40.

${ }^{22}$ ALBUQUERQUE JÚNIOR, 2013b. p. 154.

${ }^{23}$ ORTIZ, Op. Cit. (grifo meu).

${ }^{24}$ Ibidem. p. 76.

${ }^{25}$ Há um menor destaque de início ao estado de Alagoas. Já Sergipe, Bahia, Piauí e Maranhão tiveram uma adesão no projeto mais tardiamente. Cf. ALBUQUERQUE JÚNIOR, Durval Muniz de. A Feira dos Mitos: a fabricação do folclore e da cultura popular (Nordeste, 1920-1950). São Paulo: Intermeios, 2013a. p. 171.

${ }^{26}$ Ibidem. p. 179.

${ }^{27}$ Foi aluno e, posteriormente, professor na Faculdade de Direito do Recife sendo, também, poeta, jornalista e deputado federal.

${ }^{28}$ Cf. FREYRE, Fernando de Mello. O Movimento Regionalista e Tradicionalista e a seu modo também modernista: Algumas Considerações. Ci. \& Tróp.. Recife, (5(2): 175-188 jul/dez. 1977. pp. 175-188.

${ }^{29}$ ALBUQUERQUE JÚNIOR, Durval Muniz de. A invenção do Nordeste e outras artes. 5.ed. São Paulo: Cortez, 2011. p. 81.

${ }^{30}$ Ibidem. p. 81 et. seq.

${ }^{31}$ Ibidem. pp. 86-87.

${ }^{32}$ Principalmente pela forte visibilidade que a cultura nordestina ganha na década de 1930 com, por exemplo, a publicação de Casa Grande \& Senzala de Gilberto Freyre, em 1933.

${ }^{33}$ Casa Grande \& Senzala (1933), Guia Prático, Histórico e Sentimental da Cidade do Recife (1934), Sobrados e Mocambos (1936), Nordeste: Aspectos da Influência da Cana Sobre a Vida e a Paisagem (1937), Açúcar (1939), Olinda (1939).

34 Diario de Pernambuco, 01 jun. 1944. Acervo Biblioteca Nacional. (grifo meu). Notícia exatamente semelhante fora publicada no Jornal Pequeno (01 dez. 1944). O único dado acrescentado foi que a Diretoria de Estatística, Propaganda e Turismo teve ajuda da Rádio Clube de Pernambuco na gravação. Acervo Biblioteca Nacional.

${ }^{35}$ ALBUQUERQUE JÚNIOR, 2013a. p. 124.

${ }^{36}$ Ibidem. p. 123.

${ }^{37}$ CARVALHO, José Rodrigues de. Cancioneiro do Norte. 3 ed. Rio de Janeiro, Instituto Nacional do Livro, 1967. p. 336.

${ }^{38}$ Ibidem. p. 342. (grifo meu).

${ }^{39}$ MOTA, Leonardo. Cantadores: poesia e linguagem do sertão cearense. Livraria Editora Cátedra, 1976a. p. XLIV. (grifos do autor).

${ }^{40}$ ALBUQUERQUE JÚNIOR, 2013a. pp. 94-96.

${ }^{41}$ Ibidem. 


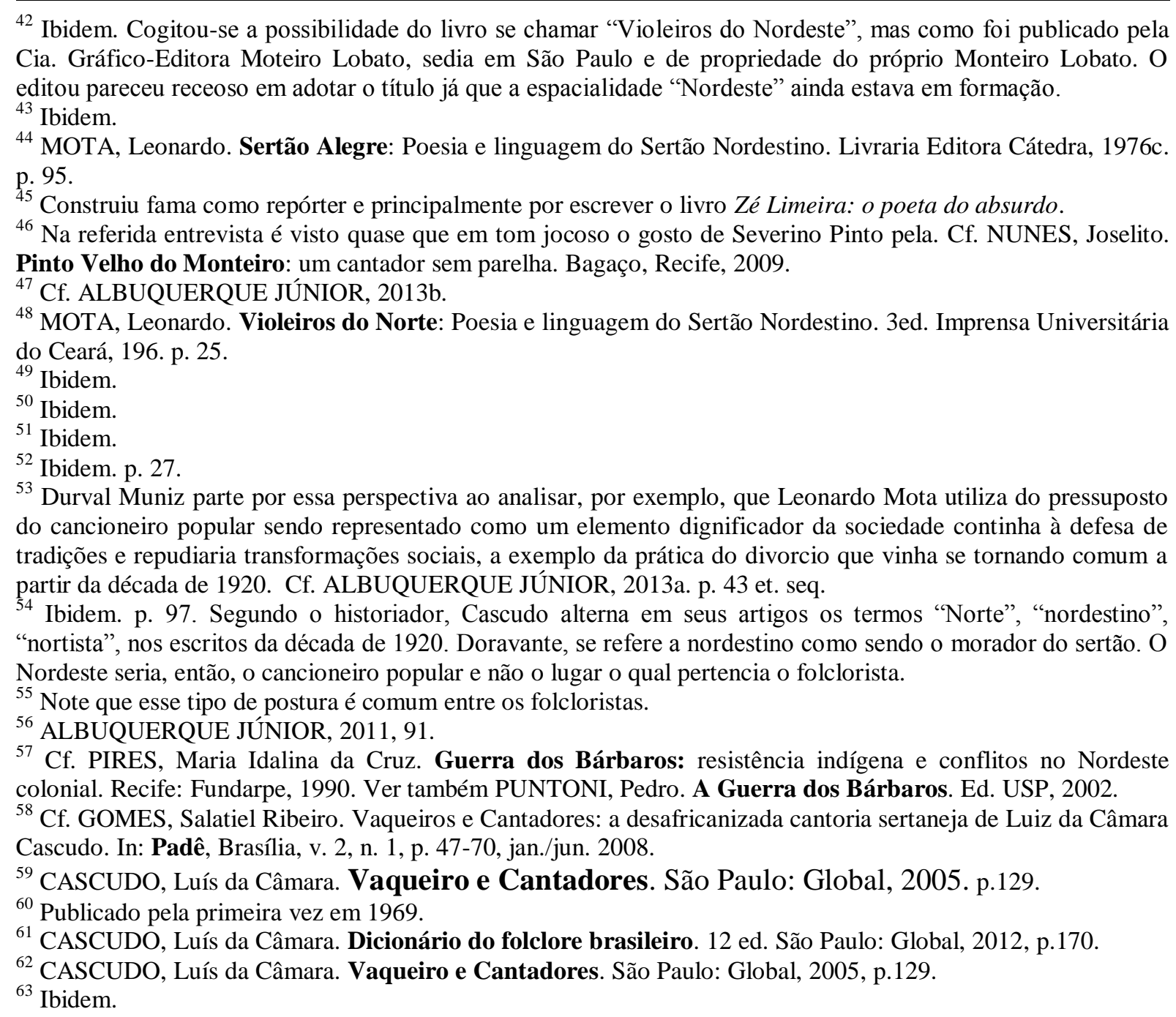

\section{Referências Bibliográficas}

ABREU, Márcia. Histórias de cordéis e folhetos. Campinas: Mercado das letras, 1999. ALBUQUERQUE JÚNIOR, Durval Muniz de. "O morto vestido para um ato inaugural": procedimentos e práticas dos estudos de folclore e cultura popular. São Paulo: Intermeios, $2013 b$.

A Feira dos Mitos: a fabricação do folclore e da cultura popular (Nordeste, 19201950). São Paulo: Intermeios, 2013a.

. A invenção do Nordeste e outras artes. 5.ed. São Paulo: Cortez, 2011.

ALMEIDA, Átila. Notas sobre a poesia popular. Campina Grande:[s.n], 1984.

AYALA, Maria Ignez Novais. No arranco do grito: (aspectos da cantoria nordestina). Ática, 1988.

AYALA, Marcos; AYALA, Maria Ignez Novais. Cultura popular no Brasil: perspectiva de análise.

Ática, 1987.

BOURDIEU, Pierre. O poder simbólico. Rio de Janeiro: Bertrand Brasil, 2003. 
CARVALHO, José Rodrigues de. Cancioneiro do Norte. 3 ed. Rio de Janeiro, Instituto Nacional do Livro, 1967

CASCUDO, Luís da Câmara. Dicionário do folclore brasileiro. 12 ed. São Paulo: Global, 2012 ,

. Vaqueiro e Cantadores. São Paulo: Global, 2005.

CERTEAU, Michel de. A beleza do morto. In:

A cultura no plural. São Paulo:

Papirus, 1995

CHARTIER, Roger. Cultura Popular revisitando um conceito historiográfico. In: Estudos Históricos, Rio de Janeiro, vol. 8, no. 16, 1995.

FILGUEIRA, Cícero Renan Nascimento. Entre a feira e o teatro: a dinâmica dos repentistas em Pernambuco (1900-1948). Dissertação (mestrado) - Universidade Federal Rural de Pernambuco, Programa de Pós-Graduação em História, 2017.

FREYRE, Fernando de Mello. O Movimento Regionalista e Tradicionalista e a seu modo também modernista: Algumas Considerações. Ci. \& Tróp.. Recife, (5(2): 175-188 jul/dez. 1977.

GOMES, Salatiel Ribeiro. Vaqueiros e Cantadores: a desafricanizada cantoria sertaneja de Luiz da Câmara Cascudo. In: Padê, Brasília, v. 2, n. 1, p. 47-70, jan./jun. 2008.

GRILLO, Maria Ângela de Faria. A Arte do Povo: Histórias na Literatura de Cordel (19001940). Jundiaí: Paco Editorial, 2015.

KOSELLECK, Reinhart. Futuro Passado: Contribuições à semântica dos tempos históricos. Puc-Rio. 2006. p. 98

MATOS, Cláudia. A poesia popular na República das Letras: Sílvio Romero folclorista. Editora UFRJ, 1994.

MOTA, Leonardo. Sertão Alegre: Poesia e linguagem do Sertão Nordestino. Livraria Editora Cátedra, 1976c

Violeiros do Norte: Poesia e linguagem do Sertão Nordestino. 3ed. Imprensa Universitária do Ceará, 1966.

NUNES, Joselito. Pinto Velho do Monteiro: um cantador sem parelha. Bagaço, Recife, 2009.

ORTIZ, Renato. Românticos e folcloristas: cultura popular. Olho d'água, 1992

PIRES, Maria Idalina da Cruz. Guerra dos Bárbaros: resistência indígena e conflitos no Nordeste colonial. Recife: Fundarpe, 1990.

PUNTONI, Pedro. A Guerra dos Bárbaros. Ed. USP, 2002.

ROMERO, Sílvio. Estudos sobre a poesia popular do Brasil. 2ed. Petrópolis: Vozes, 1977.

SILVA, Andréa Betânia da. Entre pés-de-parede e festivais : rota(s) das poéticas orais na cantoria de improviso. Tese (doutorado) - Universidade Federal da Bahia, Instituto de Humanidades, Artes e Ciências Prof. Milton Santos. I'Université Paris Ouest Nanterre, 2014.

THOMPSON, Edward Palmer. Folclore, Antropologia e História Social. In: NEGRO, Antonio Luigi; SILVA, Sergio (orgs.). As peculiaridades dos ingleses e outros artigos. São Paulo: Editora da Unicamp, 2012.

VILHENA, Luís Rodolfo. Projeto e missão: o movimento folclórico brasileiro, 1947-1964. Fundação Getulio Vargas Editora, 1997. 